\title{
6
}

\section{MÉTODO HISTÓRICO-LINGUÍSTICO PARA A DESCRIÇÃO E A ANÁLISE DO PROCESSO DE IMPLEMENTAÇÃO DO PRONOME A GENTE NO PORTUGUÊS BRASILEIRO}

\author{
HISTORICAL-LINGUISTIC METHOD FOR THE \\ DESCRIPTION AND ANALYSIS OF THE PROCESS OF \\ IMPLEMENTATION OF THE PRONOUN A GENTE \\ IN BRAZILIAN PORTUGESE
}

\author{
Paulo Ricardo Silveira Borges ${ }^{1}$ \\ Universidade Federal de Pelotas
}

Resumo: Neste trabalho apresentamos uma metodologia de caráter histórico-linguística para a descrição e a análise da inserção da forma $a$ gente no Português do Brasil. Para tanto, realizamos o mapeamento do percurso da mudança da forma pronominal a gente com base em pesquisa bibliográfica que possibilitou identificar as suas diferentes formas de utilização encontradas em textos históricos do português. As referências bibliográficas utilizadas contemplam gramáticas históricas do português, livros de filologia e de linguística histórica. Foram utilizados, também, textos de teatro de autores gaúchos escritos em diferentes épocas, correspondendo a um período de cem anos, de 1890 a 1990. Esta proposta de análise metodológica está amparada nos princípios teóricos da Gramaticalização (HOPPER; TRAUGOTT, 1993; CASTILHO, 1997), da Linguística Histórica (MATTOS E SILVA, 2008) e da Teoria da Enunciação (BENVENISTE, 1988). Com este artigo, esperamos contribuir para a descrição e a análise do processo de mudança diacrônica do pronome $a$ gente no Português do Brasil.

Palavras-Chave: Método histórico-linguístico de análise; Linguística Histórica; Português brasileiro; Pronome a gente.

1 Endereço eletrônico: paulorsborges@gmail.com. 
Abstract: In this paper we present a historical-linguistic methodology for the description and analysis of the insertion of the form a gente in the Brazilian Portuguese. For this purpose, we mapped the course of change from the pronominal form a gente based on bibliographic research that made it possible to identify its different forms of use found in historical texts of Portuguese. The bibliographic references used include historical grammars of Portuguese, books of philology and historical linguistics. Texts written for the stage by playwrights from Rio Grande do Sul (the southermost state of Brazil) were also used, comprising the period from 1890 to 1990. This proposal for methodological analysis is based on the theoretical principles of Grammaticalization (Hopper \& Traugott, 1993; Castilho, 1997), Historical Linguistics (Mattos e Silva, 2008) and Enunciation Theory (Benveniste, 1988). With this article, we hope to contribute to description and analysis of the diachronic change process of the pronoun a gente in Brazilian Portuguese.

Keywords: Historical-linguistic method of analysis; Historical Linguistics; Brazilian portuguese; Pronoun a gente.

\section{INTRODUÇÃO}

Este trabalho apresenta uma proposta metodológica para a descrição e para a análise do processo de constituição da forma pronominal a gente no Português do Brasil². Para demonstrar como ocorreu esse processo, propomos a realização de um mapeamento histórico-linguístico com o objetivo de identificar os diferentes estágios da mudança diacrônica da forma a gente no PB.

O texto foi organizado com a intenção de proporcionar, com base em critérios teórico-metodológicos, uma descrição que seja capaz de identificar os diferentes estágios linguísticos do processo de mudança em análise, como também explicar linguisticamente como se deu a constituição dessa nova forma pronominal no PB. Para a análise aqui proposta, utilizamo-nos de diferentes áreas da Linguística como as da Gramaticalização, da Linguística Histórica e da Enunciação, as quais servirão como campo de análise para demonstrar (1) o processo contínuo de gramaticalização da forma a gente, (2) a gênese de um percurso histórico-linguístico e os indícios de uma nova forma pronominal e (3) a inserção e a especialização da forma a gente como pronome pessoal do PB.

2 Português do Brasil, doravante PB, justifica-se para diferenciá-lo do Português Europeu (PE). 
As fontes e os exemplos a serem considerados neste trabalho são variados, obtidos de gramáticas históricas e de edições filológicas do português, como também de um banco de fontes históricas escritas específicas: textos de teatro escritos por autores gaúchos, correspondendo a um período histórico de cem anos, ou seja, de 1890 a $1990^{3}$.

Apresentadas essas considerações, passaremos à análise do processo de consolidação do pronome a gente no PB, a partir da identificação dos diferentes roteiros deste percurso histórico tão dinâmico e representativo.

\section{O PROCESSO CONTÍNUO DE GRAMATICALIZAÇÃO DA FORMA A GENTE}

Neste trabalho, parte-se do entendimento de que o pronome a gente gramaticalizou-se a partir de um conjunto de mudanças inter-relacionadas, de caráter unidirecional, presente em praticamente todas as mudanças que envolvem esse tipo de processo: (a) fixação da locução a gente, (b) uso de a gente com significado genérico; (c) inserção de a gente no quadro pronominal, em variação com nós, com significado específico. Nesse sentido, busca-se aqui identificar os fatores, principalmente de natureza semântico-referencial, que atuaram e atuam no processo de gramaticalização de a gente, em especial, os que dizem respeito à sua efetivação como pronome pessoal no PB e à sua utilização também em contextos de referência específica.

Um dos princípios fundamentais da Teoria Variacionista, proposta inicialmente por Weinreich, Labov e Herzog (1968) e desenvolvida por Labov no conjunto de seus trabalhos no âmbito da sociolinguística, é o de que a sistematicidade linguística não está somente em contextos categóricos, mas também em contextos de variação. Nesse aspecto, pretende-se discutir os

3 Banco de dados organizado por Borges (2004). 
princípios referentes ao processo de variação e mudança linguística atrelados à concepção de gramaticalização. Para Cezario, Marques e Abraçado (2016, p. 49), "a variação, longe de ser incompatível com o processo de gramaticalização, é prevista e explicada por um dos princípios da gramaticalização: o da estratificação". Isto é, a possibilidade de coocorrência de formas diferentes em um mesmo contexto funcional, como nos casos da variação entre os pronomes nós e a gente no PB.

Os estudos tipológicos relacionados ao processo de gramaticalização estão presentes nos textos de Heine \& Reh (1984), Hopper (1991), Hopper \& Traugott (1993), Castilho (1997), Heine (2003), Bybee (2015), entre outros, que trazem abordagens teóricas variadas para a explicação desse processo. A própria complexidade em torno do fenômeno, decorrente de divergências sobre o que realmente se entende por língua e por gramática, faz com que o alargamento de perspectivas teóricas em torno do tema seja crescente. Entretanto, para a análise de fenômenos linguísticos, a noção geral de mudança, com base na ampliação dos limites de um morfema, do léxico em direção à gramática, ou de um nível 'menos' gramatical para 'mais' gramatical está presente, em maior ou menor escala, em todos os trabalhos referidos.

Para Heine \& Reh (1984, p. 15), “a gramaticalização é um continuum evolucional", através do qual determinados itens lexicais tornam-se morfemas gramaticais, sendo unidirecional e cíclico". Hopper e Traugott (1993, p. 126), ao referirem-se à noção de contínuo, entendem que a gramaticalização também é unidirecional, uma vez que "os clines4 da gramaticalização são irreversíveis". Heine (2003, p. 579) acrescenta que a gramaticalização pode ser melhor entendida a partir da descrição de quatro mecanismos inter-relacionados e que sustentariam a idéia de unidirecionalidade: redução semântica (desemanticization),

4 Para Menon (1996, p. 623), "o cline pode ser encarado tanto do ponto de vista diacrônico, correspondendo mais ou menos à noção de deriva, como do ponto de vista sincrônico, correspondendo mais ou menos à noção de continuum". 
generalização em outros contextos (extension), perda das características morfossintáticas próprias à origem das formas (decategorialization) e redução fonética (erosion).

Entretanto, deve-se ressaltar que a proposta de gramaticalização, como um percurso unidirecional, não exclui o fato de haver, sincronicamente, etapas sucessivas de gramaticalização que corresponderiam a "camadas" (layering). No entender de Hopper \& Traugott (1993, p. 124), as “camadas" seriam os resultados sincrônicos da gramaticalização sucessiva de formas que contribuem para algum domínio. As novas camadas que emergem sucessivamente coexistiriam e interagiriam com as camadas mais antigas, que não seriam excluídas. $\mathrm{O}$ uso da forma a gente no PB, em variação com a forma nós, é um exemplo desse tipo de coexistência, uma vez que o pronome a gente, originário do item lexical gente, passa a competir com o pronome nós, sem que o substantivo tenha desaparecido. Soma-se a isso o fato de a forma a gente ter adquirido propriedades semânticas próprias à forma nós, como também reduzir-se para a 'ente ( 'ente) $)^{5}$.

Outro aspecto referente ao processo de gramaticalização diz respeito ao fato de que traços do significado lexical original tendem a permanecer na nova forma gramaticalizada, conforme o princípio da persistência (principle of pesistence de Hopper, 1991, p. 28-30). No caso específico da forma a gente, Menon (1996) e Omena \& Braga (1996) evidenciaram que a forma pronominal manteve a referência indeterminada e genérica, herdada da noção de coletividade do substantivo gente.

Castilho (1997, p. 55), ao referir-se à continuidade das inovações linguísticas, ressalta a existência de dois domínios presentes no contínuo próprios ao processo de gramaticalização: o domínio das escolhas e o domínio das determinações. No primeiro, das escolhas, diferentes formas linguísticas coocorrem e o falante escolhe uma ou outra a partir de critérios discursivos; no

5 Conforme apresentado por Borges (2004). 
segundo, das determinações, as próprias estruturas linguísticas encarregam-se de restringir as escolhas do usuário. Na gramaticalização de a gente, os dois domínios são contemplados, pelo uso variável das formas a gente vs. nós (domínio das escolhas) e pela especialização do uso da forma nova - a gente - em contextos linguísticos preferenciais, como na função de sujeito (domínio das determinações).

Quanto ao aspecto conceitual do termo gramaticalização, propõe-se aqui a seguinte definição apresentada por Castilho (1997, p. 31-32), a qual julga-se mais adequada para representar o processo envolvendo a mudança associada à forma a gente: gente (subst.) > a gente (pron. indef.) > a gente (pron. pess.).

Entendo por gramaticalização o trajeto empreendido por um item lexical, ao longo do qual ele muda de categoria sintática (=recategorização), recebe propriedades funcionais na sentença, sofre alterações morfológicas, fonológicas e semânticas, deixa de ser uma forma livre, estágio em que pode até mesmo desaparecer, como consequência de uma cristalização externa. (...) Num sentido mais amplo, a gramaticalização é a codificação de categorias cognitivas em formas linguísticas, aí incluídas a percepção de mundo pelas diferentes culturas, o processo da informação, etc. (CASTILHO, 1997, p. 31-32)

Observa-se, pela definição de Castilho, que a gramaticalização está associada a uma perspectiva de estágios, de gradação. No caso do processo de mudança envolvendo a forma a gente, aspectos linguísticos associados a essa forma, como o semântico/referencial, podem ser encontrados em diferentes pontos ao longo da sua trajetória. Entretanto, levando-se em conta o fato de que diferentes regras variáveis podem estar atuando em determinada comunidade, pode-se supor também que as mudanças em torno da forma a gente estejam relacionadas, em menor ou maior escala, às diferentes características sociais próprias aos falantes que lideram a mudança, como diferenças de idade, de gênero e de classe social. 
A gramaticalização, portanto, pressupõe a existência de variação entre formas em competição, até que a forma nova se generalize. Castilho (1997, p. 55) aproxima a variação ao caráter cíclico da gramaticalização: "parece não haver contradição em afirmar que a variação é ao mesmo tempo o ponto de partida e o ponto de chegada da mudança linguística". O princípio de estratificação (layering), apresentado por Hopper (1991, p. 22), mostra o quanto variação e gramaticalização caminham juntas, ao propor que a substituição de uma forma por outra nunca se dá totalmente. As camadas antigas (older layers) continuam a ser usadas em algumas situações, não sendo necessariamente descartadas.

A ideia de continuum ou processo inacabado, intrínseco ao termo gramaticalização, indica um conceito de gramática até certo ponto instável, uma vez que está associada a algo em movimento, não homogêneo. Bybee (2015, p. 133), nesse aspecto, destaca que o continuum está relacionado ao aumento da frequência de uso de determinada forma linguística, referindo que: "Quando uma palavra ou frase é utilizada repetidamente, nos habituamos a ela, a qual perde alguma coisa do seu impacto".

No caso específico de a gente, o processo de gramaticalização começa com o uso de a gente como pronome indefinido, nos contextos de referência genérica, difundindo-se a outros contextos, como pronome pessoal específico. A gramaticalização de a gente vem ocorrendo, até certo ponto, de forma análoga à origem do pronome vocêe no PB (cf. Faraco, 1996), bem como as possíveis reduções deste em ocê e cê (cf. Vitral, 1996; Ramos, 1997).

Tem-se que considerar, dessa forma, que o caráter contínuo, unidirecional e cíclico associado à gramaticalização não ocorre de forma categórica, mas é decorrente de um processo de variação, uma vez que as taxas de uso da forma gramaticalizada podem variar em função de determinadas características discursivas e sociais intrínsecas próprias à utilização das línguas.

6 O pronome você originou-se do seguinte processo de mudança: Vossa Mercê $>$ Vosmecê $>$ você. 


\section{A GÊNESE DE UM PERCURSO HISTÓRICO-LINGUÍSTICO E OS INDÍCIOS DE UMA NOVA FORMA PRONOMINAL}

Esta análise trata da entrada da forma a gente no sistema pronominal do $\mathrm{PB}$, caracterizando-se como um processo de múltiplas implicações gramaticais, haja vista que redimensiona as noções de "pessoas do discurso" e suas relações semânticas e funcionais. Para desenvolver este trabalho, recorremos às concepções da linguística histórica, como forma de interpretar, da melhor maneira possível, as diferentes etapas constitutivas do processo de inserção do pronome a gente no PB. Para tanto, trazemos um diversificado repertório de exemplos retirados de gramáticas históricas do português, de edições filológicas do português, de livros de linguística histórica e de um banco de fontes históricas escritas específicas: textos de teatro escritos por autores gaúchos, correspondendo a um período histórico de cem anos, ou seja, de 1890 a 1990. A pesquisa e o mapeamento dos casos possibilitaram que se identificassem os registros escritos correspondentes às formas lexicais que participaram do 'continuum evolucional' correspondente à inserção da "nova" forma pronominal $a$ gente no PB.

Ao tratar dos princípios metodológicos para a reconstrução dos materiais linguístico-históricos, Silvestre (2007, p. 35) enfatiza a importância "da possibilidade de recuperar os fatos linguísticos do passado a partir dos textos que sobreviveram na atualidade"7. Constata-se, dessa forma, que a observação diacrônica sobre determinado processo histórico, assim como as possibilidades teóricas e práticas de análises, podem constituir-se como métodos produtivos para as diferentes interpretações das mudanças, gerais e específicas, verificadas na história das línguas. Além disso, como bem destaca Machado Filho (2016, p.

\footnotetext{
7 No original: "de la posibilidad de recuperar los hechos linguísticos del pasado a partir de los textos que han sobrevivido en la actualidad" (SILVESTRE, 2007, p. 35).
} 
253), "é essencial que se conheça a história e se confrontem dados sincrônicos com comportamentos linguísticos de outros estágios da língua".

Demonstrar as diferentes etapas de um processo diacrônico não é tarefa fácil, uma vez que exige um exaustivo trabalho de pesquisa para que se possa descrever, da melhor forma, as diferentes etapas que caracterizam determinado processo. Marcotúlio et al. (2018, p. 15), ao comentar o uso histórico de textos escritos para análise metodológica linguística, destaca que "a compreensão dos processos que ocorrem no passado aliada ao conhecimento do presente mostra que a dinamicidade da língua navega em fluxos e contrafluxos, entre inovação e conservação dos aspectos linguísticos". No caso aqui específico, vários corpora foram utilizados como fontes de pesquisa, desde textos relacionados à origem da língua portuguesa, como outros textos representativos de períodos históricos periodizados até o século XX. Quanto à utilização desses corpora para descrições e análises diacrônicas, Mattos e Silva (2008) afirma que:

A Linguística histórica no sentido estrito, depende, diretamente, da filologia, uma vez que tem como base de análise inscrições, manuscritos e textos impressos no passado, que, recuperados, pelos trabalhos filológicos, tornamse os corpora indispensáveis às análises das mudanças linguísticas de longa duração. (MATTOS E SILVA, 2008, p. 10)

Acreditamos que textos escritos, de diferentes períodos, possam indicar etapas diacrônicas representativas sobre a história da língua, como também os livros que tratam de filologia portuguesa, história da língua portuguesa e linguística histórica. Todas essas fontes podem trazer importantes contribuições linguísticas para a descrição e análise dos diferentes estágios históricos do português. Oliveira (2005), nesse particular, traz a seguinte afirmação:

Quando nos voltamos para a pesquisa diacrônica, percebemos que a tarefa de selecionar os dados relevantes para a investigação da mudança linguística se torna ainda mais árdua, uma vez que não podemos contar com o testemunho dos falantes. (OLIVEIRA, 2005, p. 168) 
A forma a gente, etimologicamente, origina-se do substantivo latino gēns, gēntı̌s, que designa 'gente, raça, espécie, família, nação, povo'. Observa-se que a forma original gēns, gēnť̌s traz em si o caráter coletivo, generalizante e agrupador, referente a um conjunto de pessoas em torno de objetivos comuns. Essas características também estão presentes no campo semântico do substantivo gente, do português, que manteve as particularidades pertencentes ao substantivo latino. É importante salientar que esse caráter coletivo e genérico, atribuído ao substantivo gente, está documentado em textos pertencentes a diferentes períodos da história da língua portuguesa. A sua utilização, ora no singular, ora no plural, pode ser verificada nos seguintes trechos:

(1) Abraam fuy o primeyro dos proffetas et fuy muy sancto ome e tam amigo de deus que disso per el que eno seu linnagem seerian beeytas todalas gentes, et este connoscendo que era pouco aquello que dauam os que foron ante que el, a deus, ... (Leis de Partida - fins do século XIII. In. VASCONCELOS, 1946, p. 350)

(2) Mays ante o fezerõ saber aos omees dũu castelo que estaua sobre lo castelo de Mirra, ca em aquela guysa lhis auẽera, ca avya y mays gẽte ca em Mirra, ca a cydade era despobrada. (De Dois fragmentos de uma vida de $S$. Nicolau, do século XIV em português, publicado por Pedro de Azevedo. In. NUNES, 1967, p. 55)

Huber (1986, p. 249) traz um extrato das Cantigas de Santa Maria (do século XIII), em que o substantivo gente também aparece no plural: "Muitas vegadas o dem'enganadas ten as gentes" (Cantigas de Santa Maria, 397). Lopes (1999, p. 7), a partir de trechos extraídos também das Cantigas de Santa Maria, constata a utilização do substantivo gente, tanto no singular como no plural:

(3) No que o moço cantava | o judeu meteu mentes, e levó-lo a ssa casa, | pois se foram as gentes.

(4) mas o monge lla cuidou

fillar, mas disse-ll' a gente. 
Em outro texto do século XII, Meestre Nicolas, a meu cuydar, anotado por Hauy (1989, p. 95) para análise, verifica-se a utilização do substantivo no plural:

(5) Meestre Nicolas, a meu cuydar, é mui bõo físico, por nom saber el assi as gentes bem guarecer;

Para Lopes (1999, p. 7), a presença do substantivo gente, tanto no singular como no plural, estende-se do século XIII até o século XV. "A partir do século $\mathrm{XVI}$, a forma singular ganha terreno e o plural entra, gradativamente, em desuso, embora ainda se encontrem exemplos do tipo até o século XIX". Menon (1994, p. 192-193), ao referir-se ao emprego de a gente, apresenta fragmentos de vários textos históricos relacionados ao português: séculos XIII, A Demanda do Santo Graal; século XV, Crónica de Dom Pedro I; século XVI, excertos da literatura portuguesa presentes na Crestomatia Arcaica - Nunes (1967). Em todos os casos o substantivo gente aparece sempre com significado plural e/ou coletivo. Outro exemplo, extraído de Os Lusíadas, também pode ser observado nesse sentido:

(6) Se esta gente que busca outro hemisfério,

Cuja valia e obras tanto amaste,

Não queres que padeçam vitupério, (LUSÍADAS, I, 38, 3-5)

É interessante salientar que o substantivo gente também estabelece concordância semânticas, uma vez que, mesmo estando no singular, pode levar o predicado para o plural. Isso é possível em virtude de o substantivo gente carregar consigo o caráter coletivo, generalizante e plural. Lopes (1999, p. 8) entende que esse tipo de concordância, associada ao número gramatical, poderia

\footnotetext{
8 Levando-se em conta a existência de traços semânticos a serem atribuídos para cada um dos aspectos formais associados ao uso do substantivo gente: gênero, número e pessoa.
} 
ser um recurso utilizado no período do português arcaico ${ }^{9}$ para expressar a impessoalidade do sujeito. É importante destacar que essa concordãncia semântica é observada ainda hoje no PB, seja com o prponome a gente ("A gente estamos") como com formas como "o pessoal" ("O pessoal concordaram"). Outro exemplo desse tipo de concordância pode ser encontrado em Amaral (1955, p. 75), ao analisar as relações entre sujeito (quando é algum dos coletivos gente, família, etc) e predicado:

(7) ... com huna gente de Hespanha chamados indigentes... (DUARTE N. “Orig.", cap. 2..$^{\text {) }}$

Huber (1986, p. 281) e Nunes (1967, p. 55) ressaltam ainda que o predicado para o mesmo sujeito gente pode aparecer, numa mesma frase, uma vez no singular e outra no plural:

(8) Toda gemte te lamça de ssy com nojo de que de ty han. (Fab. 23. In: VASCONCELLOS. O livro do Esopo, 1906, p. 111)

(9) E hi morreo grandes gentes. (NUNES, 1967, p. 55 - Crestomatia arcaica)

Outro aspecto que pode ser observado em textos referentes ao português arcaico diz respeito à concordância referente ao gênero gramatical quando associado ao substantivo feminino gente.

(10) Tomarem o seu porto tanto preza Quando a gente fortíssima merece; (LUSÍADAS, I, 75, 4-5)

(11) Não sofre muito a gente generosa. (LUSÍADAS, I, 87, 5)

No sentido de homens, gente(s) também poderia relacionar-se a um predicado masculino, conforme ressalta Huber (1986, p. 280):

\footnotetext{
9 Português arcaico aqui entendido como o período que compreende as manifestações escritas da língua portuguesa referentes aos séculos XIII, XIV, XV, conforme Mattos e Silva (1989).
} 
(12) Muytas hi ha de gentes... que som auyados a perdiçon. (Textos arcaicos, Castello Perigoso. In: VASCONCELOS. Textos Arcaicos, 1959, § 14)

Essa especificidade encontrada na concordância envolvendo o gênero também foi ressaltada por Menon (1996, p. 625), ao estudar o emprego do substantivo gente como parte de um processo de gramaticalização da expressão a gente, sendo caracterizada como uma concordância do tipo "desviante" ou “ideológica"10.

Lopes (1999) compreende que os traços formais e semânticos de gênero, associados ao substantivo gente, também foram alterados devido ao processo de gramaticalização.

O traço formal de gênero no substantivo não acionava a interpretação semântica de gênero, pois a combinação com formas sintáticas no feminino não esclareceria o sexo do referente $[\phi \mathrm{FEM}]$. No processo de mudança, o gênero semântico de a gente se torna subespecificado $[\alpha \mathrm{FEM}]$, porque formas pronominais como $\mathrm{eu}$, tu/você, ele/ela tendem a combinar-se com adjetivos no masculino e/ou no feminino, dependendo do sexo do referente. (LOPES, 1999, p. 85)

Constata-se, dessa forma, que já havia nos textos arcaicos uma variabilidade de concordância associada à forma gente, tanto em número como em gênero. Essa variabilidade poderia estar indicando a existência de um processo inserido em um continuum linguístico que, no caso específico, resultaria na própria pronominalização envolvendo a forma a gente. A variação poderia estar indicando o estágio inicial do processo de mudança que, por sua vez, estaria relacionado a determinados fatores de ordem linguístico-funcional.

10 Menon (1996) utiliza o termo gramaticalização como "a transformação por que passa uma palavra lexical, autônoma, para se tornar uma palavra gramatical, presa ou funcional". 


\section{A INSERÇÃO DA FORMA A GENTE COMO PRONOME PESSOAL NO PB}

O processo de mudança diacrônica envolvendo o substantivo gente, em direção ao pronome $a$ gente, bem como as diferentes especificações atribuídas a este último, como a possibilidade de variação na concordância com o verbo ( $a$ gente é $~ a$ gente somos) ou a sua própria especialização associada a formas reduzidas como $a$ 'ente 'ente'11, mostra que a variação está presente em diferentes estágios do processo de mudança.

A forma a gente, expressa pela locução formada pelo artigo " $a$ " mais o substantivo "gente", com traços semânticos próprios ao pronome de primeira pessoa, não fora expressa nos exemplos apresentados correspondente ao período da história da língua portuguesa abordado até aqui, que vai do século XIII até o século $\mathrm{XVI}^{12}$. Porém, à medida que vai ocorrendo o desaparecimento da forma plural as gentes, começa a efetivar-se o uso da forma singular a gente, também de caráter indeterminado e coletivo.

Lopes (1999, p. 71-79), para descrever a evolução diacrônica de a gente, com base em fatores "formais-semânticos", utiliza-se de um corpus de texos escritos distribuído entre os séculos XIII e XX. A análise dos dados demonstra que a gente, como pronome pessoal, foi utilizado de forma mais efetiva a partir do século XIX. Entre o século XVI, e na primeira metade do século XIX, a forma a gente apresenta uma interpretação ambígua, ora como sinônimo de pessoa, ora como variante da forma nós.

11 A redução da forma a gente [a'ente, 'ente] tem sido constatada em análises da fala de informantes pertencentes a bancos de dados do português brasileiro. Veja-se, nesse aspecto, Borges (2004).

12 É utilizado o termo "possivelmente" porque, com exceção do trabalho de Lopes (1999), que trata do percurso de a gente em tempo real de longa duração, ainda não se tinha descrito o possível processo diacrônico de a gente. 
(13) Accudij, accudij, accudij, \& lhe perescia que repicauam ho signo, para que ha gente accudijsse aho fogo. (Vocabulário da 'Vida de Frei Pedro', de André de Resende, 1570. In. GRILLO, 1966, p. 81)

Mesmo que a gramaticalização de $a$ gente seja um processo que restrinja as possibilidades de interpretação semântica do pronome, ainda é possível haver uma interpretação ambígua com relação a sua utilização. Nota-se, no exemplo 14, extraído de uma peça de teatro do final do século XIX13, que a forma a gente pode ter uma interpretação ambígua pelo fato de seu referente não estar claramente definido, o que possibilita ser interpretado tanto como "eu" + 'toda e qualquer pessoa', como apenas "eu”.

(14) Pitorra - Vamos.... Espere, o melhor é até eu mudar já o vestido, não é? Este perfume está me arrepiando. Depois da missa do estio, a gente já pode tirar o luto. (Simões Lopes Neto, A viúva Pitorra, 1896. In: OURIQUE; RUBIRA, 2017, p. 394)

Tudo indica que o processo de cristalização da forma pronominal a gente teve início no século XIX com a especialização de seu uso, embora, de certa forma, ainda estivesse atrelado à referência genérica. Lopes (1999, p. 74-78) entende que o período em que a forma a gente mais apresenta ambiguidade interpretativa corresponde ao período no qual a forma homem (do lat. homine) passa por um processo de desaparecimento como pronome indefinido (séc. XVI). Bueno (1955, p. 208), ao analisar frases indeterminadas presentes em textos de diferentes épocas do português, enfatiza que: "Se a forma pronominal indefinida homem desapareceu do português moderno, ainda se conservam outras que vieram do mesmo período arcaico, tais como a gente, uma pessoa".

13 Exemplo retirado do corpus organizado por Borges (2004), composto por onze peças de teatro de autores gaúchos, abrangendo um período de cem anos, que se estende de 1896 até 1995, com intervalos de dez anos entre uma obra e outra. Os textos selecionados indicam os cotidianos linguísticos de grupos sociais e indivíduos que utilizam variedades urbanas, haja vista que são textos de peças de teatro em que estão representadas as falas de pessoas de diferentes estratos sociais em situações tidas como "reais" de usos em sociedade. 
Mattos e Silva (1989, p. 231-32) destaca que a forma homem, como indicador de indeterminação do sujeito, "cobre a distribuição de um pronome sujeito" a partir de um referente indeterminado, masculino ou feminino, singular ou plural. Dias (1953, p. 94), ao abordar esse tema, diz que as formas homem e pessoa equivaliam "até certo ponto" ao on francês ${ }^{14}$ : "Ha-de dizer-se ‘até certo ponto', por isso que taes expressões tem uso muito mais restricto, sendo que o seu emprego só tem lugar, por via de regra, quando se falla do que acontece geralmente".

Nota-se, portanto, que o autor evidencia o caráter generalizante atribuído ao on francês, a partir do processo de gramaticalização de nome $>$ pronome ${ }^{15}$. Essa transição também é ressaltada em gramáticas históricas do português, bem como em trabalhos associados à dialetologia brasileira. Nunes (1956, p. 265) fala da utilização do substantivo homem, igualmente como indefinido, prática transmitida durante a evolução do português; Vasconcellos (1959, p. 61) ressalta a evolução lat. homine > on, através do que chamou de "pronome substantivo"; Amaral (1955, p. 73) refere-se a outras formas pronominais, salientando a utilização de variantes utilizadas para a primeira pessoa do plural, referentemente ao seu estudo sobre o dialeto caipira paulista: "a gente, $u^{n} a$ pessoa (ambas correspondentes ao francês on)". Said Ali (1964), objetivando especificar melhor a relação entre a transição ocorrida a partir dos vocábulos homem $>$ on e gente > a gente, faz a seguinte consideração:

Têm de comum estes dois pronomes o mostrarem visivelmente que se originaram cada qual de um substantivo; ou, melhor, são nomes que assumem caráter pronominal quando usados, não já na acepção própria, mas para indicar agente vago e indeterminado. (SAID ALI, 1964, p. 116)

\footnotetext{
14 Salienta-se também a existência das formas pronominais indefinidas uno (una) do espanhol, one do inglês e man do alemão.

15 Castilho (1997, p. 37) diz serem duas as fontes de gramaticalização dos pronomes pessoais: "(i) demonstrativos para a terceira pessoa determinada, e (ii) expressões nominais para a terceira pessoa indeterminada (cf. Lat. homo $>$ Port. Arc. ome, Fr. on), para a primeira pessoa (cf. Port. a gente em lugar de eu/nós) ou para a segunda pessoa (cf. Vossa Mercê > Você)".
} 
O autor também ressalta a utilização de $a$ gente na linguagem "familiar da atualidade", como exemplo de indeterminação do sujeito ${ }^{16}$. Entretanto, já era possível encontrar, em determinadas gramáticas históricas, comentários acerca da utilização de a gente como forma de manifestação popular associada ao pronome de primeira pessoa nós. Dias (1953, p. 73) refere o seguinte: “Na conversação emprega-se a gente com o valor do pronome nós: Venha com a gente". Nunes (1956, p. 265) faz o seguinte comentário: “No povo o vocábulo gente tem valor colectivo, valendo pelos pronomes eu e tu ou ele, nos casos em que a língua culta usa nós".

Schmitz (1973, p. 640) entende que o significado indefinido atribuído à forma a gente poderia ter o mesmo significado do on francês. Enfatiza que nas sentenças (i) a gente dorme muito nas férias, (ii) o homem dorme muito e (iii) essa pessoa dorme muito, as palavras homem e essa pessoa referem-se à terceira pessoa do singular, enquanto a forma a gente refere-se à primeira pessoa do singular ou plural. A sentença a gente dorme muito poderia, no sentido utilizado pelo on francês, ser entendida como dorme-se muito nas férias, com referente indefinido.

Evidencia-se, assim, o "início" da inserção no quadro dos pronomes pessoais do PB da forma pronominal a gente, caracterizando-se como um processo de mudança resultante da alternância entre a gente e nós. A forma a gente, inicialmente de caráter indeterminado, passa a adquirir características determinadas.

16 O termo "atualidade" deve ser levado em conta, tomando-se como base o ano de publicação da obra de Said Ali, Gramática histórica da língua portuguesa, utilizada neste trabalho. A primeira edição constitui-se de dois volumes autônomos: 1921, ao publicar a Lexeologia do português histórico (os sons e sua representação e os vocábulos); 1923, ao publicar a Formação de palavras e sintaxe do português histórico (formação de palavras, sintaxe e apêndices). 


\section{A ESPECIFICAÇÃO DE A GENTE COMO PRONOME PESSOAL DO PB}

Schmitz (1973, p. 639) destaca que muitos dos registros feitos por gramáticos sobre o uso de a gente, como uma forma utilizada no colóquio normal ou por falantes de baixa escolaridade, deixam de enfatizar a verdadeira amplitude do seu uso.

A palavra [a gente] é, entretanto, empregada por ambos os falantes do português, escolarizados e não-escolarizados, tanto em ocasiões semiformais como informais; a gente é empregado por [falantes de] todas as classes sociais. (SCHMITZ, 1973, p. 640)

Levando em conta a manifestação oral da linguagem, Nascentes (1953, p. 170) apresenta um estudo dialetológico sobre o linguajar carioca, no qual faz algumas considerações sobre o uso de a gente. Mesmo tratando a gente como um pronome indefinido, faz considerações sobre o seu uso nas "classes incultas", apresentando exemplos de concordância como "a gente vamos hoje", que muito contribui para caracterizar a forma a gente como um pronome pessoal:

A pessoa que está falando tem em mente a sua pessoa e as mais, com ela associadas; daí por silepse o verbo deixar a concordância formal exigida pela terceira do singular e vir na primeira do plural. (NASCENTES, 1953, p. 170)

Observa-se no exemplo "a gente vamos hoje" que o falante, ao utilizar a gente em lugar do pronome nós, de primeira pessoa plural, mesmo deixando de lado a concordância formal, não abre mão da concordância semântica: “...a pessoa que está falando tem em mente a sua pessoa e as mais". Evidencia-se, assim, um plural associativo relacionado à noção de "eu-ampliado" (cf. Benveniste, 1988, p. 256-58), o que caracterizaria a gente como um pronome pessoal. 
Destaca-se também que o significado indeterminado, atribuído ao uso de a gente, continua presente na língua portuguesa, com características genéricas, em frases em que a referência inclui todas as pessoas do discurso.

(15) Efetivamente... a gente vive sem uma finalidade. (In: BORGES, Luís Pery. Seis anos de rádio: história anedótica de Pery \& Estellita - sketches e crônicas. Porto Alegre: Thurmann, 1942, p. 90) ${ }^{17}$

A utilização de a gente, nesse caso, expressa um sentido mais genérico, uma vez que a pessoa que fala está associada a um grupo não delimitado, a partir do menor comprometimento do "eu", através de sua inserção em um grupo grande, sem limitação definida. A forma a gente pode ser interpretada também, dependendo do contexto, como substitutiva do "eu", como em casos em que a pessoa fale muito de si, podendo ser utilizado como um recurso estilístico. Observe-se no exemplo extraído da peça de teatro "A Viúva Pitorra", do final do século XIX, escrita por Simões Lopes Neto:

(16) [Cidreira mostrando para Pitorra uma coroa de flores que ela tinha encomendado para colocar no túmulo do falecido Sr. Pitorra.]

Pitorra (Pausa e fazendo Cidreira exibir a coroa em todos os sentidos) - Mais para trás! Pra frente! Um pouco acima! À direita! Esquerda! Ah! Hep! Mais baixo... Mais um pouco... Assim! (Pausa.) Ora, seu Cidreira... Servir, serve... Mas esta forma é já tão vista... Não produz efeito... Parece que a gente não sentiu bastante... E esse letreiro... Eu lhe tinha dito - Eterna saudade...

Cidreira - E aqui está - Eternas saudações - é muito mais próprio; é como quem diz: Adeus! [...] (Simões Lopes Neto, A viúva Pitorra, 1896. In: OURIQUE; RUBIRA, 2017, p. 400)

Ressalta-se que, no exemplo 16, o verbo está no pretérito perfeito caracterizando bem o "eu" inequívoco. Se o verbo estivesse no pretérito imperfeito ou no presente, a interpretação possibilitaria que estivessem incluídos, além do "eu”, qualquer outra pessoa.

17 Exemplo retirado do corpus organizado por Borges (2004). 
A evolução histórico-diacrônica de a gente, considerando-se a origem do substantivo gente, bem como sua utilização em vários textos, de diferentes períodos da história da língua portuguesa, mostra que implicações de caráter semântico-referencial estão presentes em sua trajetória, a ponto de a forma a gente ainda manter o caráter genérico, próprio à forma original. Pode também ser empregada como pronome pessoal "pleno", através da aquisição de traços semânticos de primeira pessoa do plural e, em muitos casos, também do singular. Constata-se, assim, o início de uma restrição formal e uma especificação referencial atrelada ao uso da forma pronominal a gente, a ponto da locução nominal a gente só ser utilizada no singular, bem como especializar-se como forma de indeterminação do sujeito ${ }^{18}$.

A evolução ${ }^{19}$ e os novos significados funcionais que possibilitaram que a forma a gente, de caráter indeterminado, se integrasse plenamente no quadro dos pronomes pessoais já foram observados e caracterizados com as seguintes terminologias: pronominalização, conforme Omena (1986); gramaticalização, conforme Menon (1996), Omena \& Braga (1996), Lopes (1999), Zilles (2002, 2003); pessoalização, conforme Borges (2004).

Na sequência do desenvolvimento do que vem aqui sendo analisado, utilizaremos um conjunto de exemplos com usos do pronome a gente, retirados do corpus "Peças de teatro de autores gaúchos: do século XIX ao século XX", organizado por Borges (2004), que compõe acervo composto de onze peças de teatro escritas por autores gaúchos, abrangendo um período de cem anos, que se estende de 1896 até 1995, com intervalos de dez anos entre uma obra e outra. Os exemplos indicam o uso do pronome a gente tanto em contextos de referência

\footnotetext{
18 Menon (1996, p. 626) mostra as etapas dessa especialização, denominadas pela autora como "cadeia de transformação".

19 O termo 'evolução' foi utilizado por Lopes (1999, p. 67) no sentido de "evolução diacrônica de a gente a partrir das especificidades das entradas lexicais (os traços primitivos) do substantivo gente e da forma pronominal a gente".
} 
genérica, que caracterizaremos aqui como "não-específicos", como em contextos de referência "específica".

Para a caracterização das especificações semântico-referenciais atreladas ao uso da forma a gente, faremos uso dos preceitos teóricos propostos por Benveniste (1988) que apresenta o sistema pronominal pessoal levando em conta dois grupos paradigmáticos: o do "eu/tu" e o do "ele". Tem-se, assim, a especificação de "pessoa" formulada em oposição à de "não-pessoa", com a distinção das duas primeiras pessoas ("eu" e "tu"), da terceira pessoa ("ele"). Para Benveniste (1988, p. 256), os pronomes "eu" e "tu" são os únicos que indicam realmente a categoria de "pessoa", ao destacar que:

Se não pode haver vários "eu" concebidos pelo próprio "eu" que fala, é porque "nós" [a gente] não é uma multiplicação de objetos idênticos mas uma junção entre o "eu" e o "não-eu", seja qual for o conteúdo desse "não-eu"20. [...] A presença do "eu" é constitutiva do "nós" [a gente]. (BENVENISTE, 1988, p. 256)

Sendo assim, o pronome a gente indicaria um plural que deve ser interpretado como "eu" somado a uma ou mais pessoas, no qual o ouvinte pode ou não estar incluído. A gente não é plural de "eu", mas apenas inclui uma referência a "eu" e é plural, já que envolve o "eu" e interlocutor ou o "eu" e outra(s) pessoa(s). O pronome a gente traz em si uma reunião de diferentes pessoas, sempre com a presença do locutor, somado ao interlocutor, ou combinado também com a "não-pessoa" (Cf. Benveniste, 1988, p. 258). Dessa forma, ao integrar-se ao sistema dos pronomes pessoais do PB, em competição com nós, a forma a gente passa a comportar-se como um verdadeiro pronome.

A forma a gente também representa um coletivo genérico, intrínseco à palavra originária gentem, desprovida do traço plural de numerosidade, uma vez que se refere à classe como um todo, ou seja, "eu” e todo indivíduo pertencente

20 A inserção de $a$ gente deve-se à proposta apresentada aqui de aproximação semântica, para efeito de análise, entre nós e a gente. 
à classe referida. Por outro lado, tem-se o referente genérico não-específico, identificado com a noção de numerosidade, justamente por representar qualquer membro da classe, isto é, "um" como representante da classe.

Para os fins aqui propostos, podemos caracterizar as diferentes possibilidades de utilização do pronome a gente, levando-se em conta a estrutura enunciativa proposta por Benveniste (1988):

Quadro 1: Categorias semântico-referenciais para o uso do pronome a gente no PB conforme sistema pronominal pessoal proposto por Benveniste (1988)

a) a gente genérico:"eu" + todo e qualquer indivíduo que compreende o discurso ["pessoa" ou "não-pessoa"]

b) a gente plural exclusivo: baixo grau de pessoalização [a gente $=e u+$ outro(s) (não-pessoa)]

c) a gente plural inclusivo: médio grau de pessoalização $[a$ gente $=e u$ $+t u / v o c \hat{e}$ (pessoa) + outro(s) (não-pessoa)]

c) $^{1}$ a gente plural inclusivo: alto grau de pessoalização $[$ a gente $=e u+$ tu/você (pessoa)]

d) a gente singular "eu": mais alto grau de pessoalização [a gente $=e u$ (pessoa)]

Para caracterizar cada uma das categorias referidas anteriormente no Quadro 1, trazemos exemplos retirados dos textos de teatro que integram o corpus "Peças de teatro de autores gaúchos: do século XIX ao século XX", que demonstram plenamente o processo de cristalização da forma a gente como pronome pessoal no $\mathrm{PB}$, bem como as diferentes possibilidades semânticoreferenciais propostas a partir das categorias gramaticais referidas:

a) genérico: "eu" + todo e qualquer indivíduo que compreende o discurso (pessoa ou não-pessoa)

Peça de Teatro A ciumenta velha (Joaquim Alves Torres) - 1905.

Luciana - De modo que nunca se encontraram?

Nuno - Encontremo-nos na tal madrugada. Então ele prometeu justificar a sua ausência. Disse-me que tinha vindo de um velório e obrigou-me a jurar uma discrição, isto é, o tal túmulo. Apre! Olhem que é difícil a gente se fazer de túmulo. 
(HEEMANN, C. Teatro Social: O ultraje, O trabalho, A ciumenta velha. Porto Alegre: IEL, 1989, p. 184.)

b) plural exclusivo: $e u+o u t r o(s)$ (não-pessoa)

Peça de Teatro A ponte (Valdir Ruzicki) - 1962

Pai - [...] Um dia um colega da repartição me propôs um negócio que ia dar muito dinheiro. A gente cobrava do pessoal que ia na repartição para que os processos andassem depressa. Até se fez uma tabela de preços. Era eu quem fazia a cobrança. A coisa foi dando certo até que descobriram a marmelada. Eu levei toda a culpa, porque era eu quem cobrava. O outro conseguiu se safar da encrenca [...]

(RUZICKI, Valdir. A ponte. Porto Alegre: Livraria do Globo, 1962, p. 24.)

c) plural inclusivo: $e u+t u / v o c e ̂($ pessoa) + outro(s) (não-pessoa)

Peça de Teatro Pode ser que seja só o leiteiro lá fora (Caio Fernando Abreu) $-1974$

Alice Cooper - Mas que loucura é essa? Agora que estou reparando. Todo mundo colorido, maquiado, parece uma festa. Quem foi que teve essa idéia máravilhosa?

Mona - Fui eu. Já que a gente vai mesmo ficar aqui a noite toda, achei que era melhor fazer uma festa à fantasia. De feia basta aquela cidade lá fora, não é?

(ABREU, Caio Fernando. Pode ser que seja só o leiteiro lá fora. In. Teatro completo. Porto Alegre: Sulina, 1997, p. 25.)

c1) plural inclusivo: $e u+t u / v o c e ̂($ pessoa)

Peças de Teatro Bye bye sweet home! A barra do tribunal, Casinha pequenina, Tudo no divã (Ivo Bender) - 1983

Júlia - Guardo aqui. $\mathrm{O}$ troco miúdo fica contigo.

Romeu - Agora vamos. A gente pode usar o apartamento até a meia-noite. Não mais. Depois meu amigo chega.

Júlia - Romeu.

Romeu - Que é?

Júlia - Quem sabe a gente deixa isso pra depois?

(BENDER, Ivo Cláudio. Bye, bye sweet home! In. Nove textos breves para teatro. Porto Alegre: Editora da UFRGS, 1985, p. 70-71.)

d) singular "eu": $e u$ (pessoa)

Peça de Teatro A coisa certa (Júlio Conte) - 1995

Gisela - Hoje não tô muito a fim... Tô precisando sair um pouco. [quase enlouquecida] A gente precisa se divertir! A gente tem que se divertir! (CONTE, Júlio. A coisa certa. Porto Alegre: WS Editor, 1998, p. 106.)

Identificamos, assim, o processo de cristalização de a gente como pronome pessoal do PB, levando-se em conta suas características semântico-referenciais e 
suas diferentes possibilidades de realizações. Além disso, apresentamos o mapeamento e a identificação dos diferentes estágios em torno da sua inserção no quadro pronominal do PB.

\section{CONSIDERAÇÕES FINAIS}

A proposta deste trabalho foi mapear o percurso de mudança diacrônica da forma pronominal a gente no PB. Para tanto, realizamos uma exaustiva pesquisa bibliográfica para identificar as suas diferentes possibilidades de utilização encontradas em textos de diferentes períodos históricos do português, bem como trazer referências histórico-gramaticais e diacrônicas presentes tanto em gramáticas como em diferentes livros de filologia do português e de linguística histórica. Além disso, apresentamos também exemplos retirados de peças de teatro de autores gaúchos, correspondentes a um período histórico que vai do final do século XIX ao final do século XX.

É importante salientar que, pelo caráter dinâmico do fenômeno de pronominalização e de pessoalização da forma a gente, assim como pelo continuum que representa a mudança linguística referente ao processo diacrônico aqui analisado, a proposta descritiva de mapeamento apresentada representa apenas uma parte desse processo. Temos ainda muita estrada pela frente, haja vista que o caminho nos leva para outros desafios, entre os quais o de mapear, analisar e compreender melhor os estágios mais adiantados dessa mudança, próprios às novas formas reduzidas de utilização da forma pronominal a gente, em especial na fala, como $a^{\prime}$ ente, 'ente, 'te, formas essas que buscam regularizar o sistema dos pronomes pessoais no PB.

Talvez em um futuro não muito distante, possamos também identificar em textos literários, gramáticas do $\mathrm{PB}$ e em diferentes livros de linguística histórica, não somente o uso do pronome a gente como também essas novas 
formas reduzidas para a sua utilização, haja vista que elas já se fazem presentes, mesmo que timidamente, em alguns textos de crianças e jovens estudantes de escolas brasileiras, assim como em textos escritos nas redes sociais, tais como Facebook, YouTube, WhatsApp, Instagram, entre outros.

\section{REFERÊNCIAS}

ABREU, Caio Fernando. Pode ser que seja só o leiteiro lá fora. In: Teatro completo. Porto Alegre: Sulina, 1997.

AMARAL, Amadeu. O dialeto caipira. São Paulo: Anhembi, 1955.

BENDER, Ivo Cláudio. Bye, bye sweet home! In: Nove textos breves para teatro. Porto Alegre: Editora da UFRGS, 1985.

BENVENISTE, Émile. Problemas de linguística geral I. Campinas: Pontes, 1988.

BORGES, Luís Pery. Seis anos de rádio: história anedótica de Pery \& Estellita - sketches e crônicas. Porto Alegre: Thurmann, 1942.

BORGES, Paulo Ricardo Silveira. A gramaticalização de a gente no português brasileiro: análise histórico-social-linguística da fala das comunidades gaúchas de Jaguarão e Pelotas. Programa de Pós-Graduação em Letras, Universidade Federal do Rio Grande do Sul, Porto Alegre, 2004.

BUENO, Francisco da Silveira. A formação histórica da língua portuguesa. Rio de Janeiro: Livraria Acadêmica, 1955.

BYBEE, Joan Lea. Language change. Cambridge: Cambridge University Press, 2015.

CAMÕES, Luís de. Os Lusíadas. Rio de Janeiro: Livraria Francisco Alves, 1930.

CASTILHO, Ataliba Teixeira de. A gramaticalização. Estudos Linguísticos e Literários, Salvador, n. 19, 1997, p. 25-63.

CEZARIO, Maria Maura; MARQUES, Priscilla Mouta; ABRAÇADO, Jussara. Sociofuncionalismo. In. Sociolinguística, sociolinguísticas: uma introdução. São Paulo: Contexto, 2016.

CONTE, Júlio. A coisa certa. Porto Alegre: WS Editor, 1998.

DIAS, Augusto Epiphanio da Silva. Syntaxe histórica portuguesa. 3. ed. Lisboa: Livraria Clássica Editora, 1953.

FARACO, Carlos Alberto. O tratamento "você" em português: uma abordagem histórica. Fragmenta, Curitiba, n. 13, p. 51-82, 1996.

GRILLO, Samuel da Costa. Vocabulário da 'Vida de Frei Pedro'. Rio de Janeiro: Instituto Nacional do Livro / MEC, 1966. 
HAUY, Amini Boainain. História da língua portuguesa: I. Séculos XII, XIII e XIV. São Paulo: Ática, 1989.

HEEMANN, Cláudio. Teatro Social: O ultraje, O trabalho, A ciumenta velha. Porto Alegre: IEL, 1989.

HEINE, Bernd. Grammaticalization. In. JOSEPH, Brain; JANDA, Richard. (eds.) The Handbook of Historical Linguistics. Oxford: Blackwell, p. 575-601, 2003.

HEINE, Bernd; REH, Mechthild. Grammatical categories in African Languages. Hamburg: Helmut Buske, 1984.

HOPPER, Paul. On some principles of grammaticalization. In: TRAUGOTT, Elizabeth Closs; HEINE, Bernd. (eds.) Approaches to Grammaticalization. Amsterdam: J. Benjamins. v. 1, p. 17-35, 1991.

HOPPER, Paul; TRAUGOTT, Elizabeth Closs. Grammaticalization. Cambridge: Cambridge University Press, 1993.

HUBER, Joseph. Gramática do português antigo. Coimbra: Fundação Calouste Gulbenkian, 1986.

LOPES, Célia Regina dos Santos. A inserção de "a gente" no quadro pronominal do português: percurso histórico. Tese de Doutorado, Faculdade de Letras, Universidade Federal do Rio de Janeiro, Rio de Janeiro, 1999.

MACHADO FILHO, Américo Venâncio Lopes. Diversidade linguística do português: entre faces. In: Anais do Seminário Ibero-americano de Diversidade Linguística. Brasília: Iphan, 2016, p. 249-262.

MARCOTULIO, Leonardo Lennertz. Filologia, história e língua: olhares sobre o português medieval. São Paulo: Parábola, 2018.

MATTOS E SILVA, Rosa Virgínia. Estruturas trecentistas: elementos para uma gramática do português arcaico. Lisboa: Imprensa Nacional-Casa da Moeda, 1989.

MATTOS E SILVA, Rosa Virgínia. Caminhos da linguística histórica: ouvir o inaudível. São Paulo: Parábola, 2008.

MENON, Odete Pereira da Silva. Analyse sociolinguistique de l'indetermination du sujet dans lê portugais parle au Bresil, a partir dês donnees du NURC/SP. Tese de Doutorado. Département de Recherches Linguistiques, Universidade de Paris VII, Paris, 1994.

MENON, Odete Pereira da Silva. A gente: um processo de gramaticalização. Estudos linguísticos, XXV, Taubaté. Anais de seminários do GEL. Taubaté, p. 622-628, 1996.

NASCENTES, Antenor. O linguajar carioca. 2. ed. Rio de Janeiro, 1953.

NUNES, José Joaquim. Compêndio de gramática histórica portuguesa: fonética e morfologia. 4. ed. Lisboa: Livraria Clássica Editora, 1956.

NUNES, José Joaquim. Crestomatia arcaica: excertos da literatura portuguesa desde o que mais antigo se conhece até ao século XVI. 7. ed. Lisboa: Livraria Clássica Editora, 1967.

OLIVEIRA, Marco Antônio de. "Nem tudo que reluz é ouro": língua escrita e mudança linguística. Scripta, Belo Horizonte, v. 8, n. 16, p. 165-175, 2005. 
OMENA, Nelise Pires de. A referência variável da primeira pessoa do discurso no plural. In: NARO, Anthony Julius. Relatório final de pesquisa: projeto subsídios do projeto censo à educação. Rio de Janeiro: UFRJ, v. 2, 1986, p. 286-319.

OMENA, Nelise Pires de; BRAGA, Maria Luiza. A gente está se gramaticalizando? In: MACEDO, Alzira Tavares de; RONCARATI, Cláudia; MOLLICA, Maria Cecília. (Orgs.). Variação e discurso. Rio de Janeiro: Tempo Brasileiro, 1996.

OURIQUE, João Luis Pereira; RUBIRA, Luís. Teatro: século XIX. João Simões Lopes Neto. Porto Alegre: Instituto Estadual do Livro: Zouk, 2017.

RAMOS, Jânia Martins. O uso das formas você, ocê e cê no dialeto mineiro. In: HORA, Dermeval da. Diversidade lingüística no Brasil. João Pessoa: Idéia, p. 43-60, 1997.

RUZICKI, Valdir. A ponte. Porto Alegre: Livraria do Globo, 1962.

SAID ALI, Manuel. Gramática histórica da língua portuguesa. 3. ed. São Paulo: Edição Melhoramentos, 1964.

SCHMITZ, John Robert. The linguistic flexibility of "a gente" in Portuguese. Hispania [Notes on usage], 1973, p. 639-644.

SILVESTRE, Juan Camilo Conde. Sociolinguística histórica. Madrid: Gredos, 2007.

VASCONCELOS, Carolina Michaëlis. de. Lições de filologia portuguesa: segundo as preleções feitas aos cursos de 1911/12 e de 1912/13. Lisboa: Edição da Revista de Portugal, Série A, Língua Portuguesa, 1946.

VASCONCELOS, José Leite de. O livro do Esopo: fabulário português medieval, publicado conforme manuscrito do século XIV. Lisboa: Imprensa Nacional, 1906.

VASCONCELOS, José Leite de. Lições de filologia portuguesa. 3. ed. Rio de Janeiro: Livros de Portugal, 1959.

VITRAL, Lorenzo. A forma cê e a noção de gramaticalização. Revista Estudos Lingüísticos, Belo Horizonte, n. 4, v. 1, p. 115-124, jan./jun. 1996.

ZILLES, Ana Maria Stahl. Grammaticalization of a gente in Brazilian Portuguese. In: JOHNSON, Daniel Ezra; SANCHES, Tara. (eds.). University of Pennsylvania Working Papers in Linguistics (Papers from NWAV 30), v. 8, n. 3, 2002, p. 297-310.

ZILLES, Ana Maria Stahl. Real, apparent, or both? Three types of evidence for a grammaticalization change in progress in Brazilian Portuguese. Philadelphia: VWAV 32, University of Pennsylvania, 2003.

WEINREICH, Uriel; LABOV, William; HERZOG, Marvin. Empirical foundations for a theory of language change. In: LEHMANN, Winfred; MALKIEL, Yakov. (eds.) Directions for historical linguistics. Austin: University of Texas Press, 1968.

Nota do editor:

Artigo submetido para avaliação em: 04 de setembro de 2020.

Aprovado em sistema duplo cego em: 08 de fevereiro de 2021. 